Trinidad Vázquez Ruano

Universidad de Jaén

tvazquez@ujaen.es

\title{
Comportamientos desleales en la comercializacion del aceite de oliva. La protección del consumidor
}

\author{
Ochrona konsumenta przed nieuczciwymi praktykami \\ przy wprowadzaniu do obrotu oliwy z oliwek
}

\begin{abstract}
RESUMEN
El mercado es un núcleo de información de indudable importancia para el consumidor en la medida en que en él confluyen los elementos esenciales de la oferta y de la demanda. En este panorama, el empresario va a difundir mensajes tendentes a captar la atención del destinatario y que tienen por pretensión la promoción de sus productos, como lo es el aceite de oliva en el sector oleícola, a fin de que finalmente actúe y contrate o, en su caso, lo adquiera. La Directiva 2005/29/ $\mathrm{CE}$, de 11 de mayo, relativa a las prácticas comerciales desleales de las empresas en sus relaciones con los consumidores en el mercado interior, ha hecho necesaria la modificación de la norma española que regula la competencia en el mercado y la actividad promocional. Circunstancia que ha aprovechado el legislador nacional para incluir la previsión de la publicidad contraria a Derecho como práctica desleal y que ha supuesto la unificación del sistema de acciones judiciales previstas frente a los comportamientos ilícitos en el mercado.
\end{abstract}

Palabras clave: competencia desleal; publicidad; aceite de oliva; comercialización; protección del consumidor

\section{INTRODUCCIÓN}

Las imposiciones normativas recogidas tanto en la Directiva 2005/29/CE relativa a las prácticas comerciales desleales de las empresas en sus relaciones con los consumidores en el mercado interior ${ }^{1}$, como en la Directiva 2006/114/CE

${ }^{1}$ Directiva 2005/29/CE, de 11 de mayo, relativa a las prácticas comerciales desleales de las empresas en sus relaciones con los consumidores en el mercado interior (Directiva sobre las prácticas comerciales desleales. DOUE L 149, de 11 de junio), que modifica la Directiva 84/450/ 
sobre publicidad engañosa y publicidad comparativa ${ }^{2}$, se han traspuesto al ordenamiento jurídico español con la aprobación de la Ley $29 / 2009^{3}$, lo que ha supuesto la modificación del régimen legal de la competencia desleal y de la publicidad para la mejora de la tutela y garantía de los intereses de los consumidores y usuarios de acuerdo con las exigencias del mercado y, al mismo tiempo, de los operadores económicos que actúan en él ${ }^{4}$. En particular, respecto de la materia que nos ocupa, la norma indicada altera el régimen jurídico de las conductas y comportamientos desleales ${ }^{5}$ y el de la actividad publicitaria ${ }^{6}$, incluyendo una regulación unitaria de la deslealtad de los actos de engaño y de las prácticas agresivas, además de normas procesales que prevén la interposición de la acción de cesación frente a las prácticas desleales que perjudican los intereses económicos de los consumidores en el tráfico empresarial ${ }^{7}$.

En relación con la materia que abordamos en el presente trabajo, hemos de partir del concepto de publicidad de carácter comercial, lo que significa que siguiendo el tenor de la norma va a ser: "toda forma de comunicación realizada por una persona física o jurídica, pública o privada, en el ejercicio de una actividad comercial, industrial, artesanal o profesional con el fin de promover de forma directa o indirecta la contratación de bienes muebles o inmuebles, servicios, derechos y obligaciones". A este respecto, para poder calificar un anuncio como publicitario es preciso que concurra un doble presupuesto: que el mensaje haga posible una comunicación entre los usuarios o consumidores y el anunciante; y que el establecimiento de los anuncios se prevea con la intención de promocionar los bienes, servicios o la imagen del empresario-anunciante en el mercado, bien sea de modo directo o indirecto. En cuanto al primero de los requisitos, conviene aclarar que la norma permite cualquier forma

CEE, la Directiva 97/7/CE, la Directiva 98/27/CE y la Directiva 2002/65/CE, y el Reglamento (CE) 2006/2004.

${ }^{2}$ Directiva 2006/114/CE del Parlamento Europeo y del Consejo, de 12 de diciembre, sobre publicidad engañosa y publicidad comparativa (DOUE L 376 de 27 de diciembre).

${ }^{3}$ Ley 29/2009, de 30 de diciembre, por la que se modifica el régimen legal de la competencia desleal y de la publicidad para la mejora de la protección de los consumidores y usuarios (BOE núm. 315 de 31 de diciembre).

${ }^{4}$ Esta norma ha supuesto la modificación de los siguientes textos normativos: Real Decreto Legislativo 1/2007, de 16 de noviembre, por el que se aprueba el texto refundido de la Ley General para la Defensa de los Consumidores y Usuarios y otras leyes complementarias (BOE núm. 287 de 30 de noviembre, en adelante TRLDCU); la Ley 7/1996, de 15 de enero, de Ordenación del Comercio Minorista (BOE núm. 15, de 17 de enero 1996, en adelante LOCM); la Ley 34/1988, de 11 de noviembre, General de Publicidad (BOE núm. 274, de 15 de noviembre, en adelante LGP); y la Ley 3/1991, de 10 de enero, de Competencia Desleal (BOE núm. 10, de 11 de enero, en adelante LCD).

${ }^{5}$ Arts. 5 a 17 de la LCD. Son los actos de engaño, de confusión, de denigración, la imitación, la explotación de la reputación ajena, la violación de secretos, la inducción a la infracción contractual, la violación de normas, la discriminación y dependencia económica, la venta a pérdida y las prácticas agresivas.

\footnotetext{
${ }^{6}$ Art. 18 de la LCD.

${ }^{7}$ Arts. 32 a 36 de la LCD.
} 
de comunicación que sea de naturaleza colectiva o individual, así serán actividades promocionales tanto aquéllas cuyos destinatarios sea un colectivo indeterminado de sujetos, como los casos en los que la comunicación tenga carácter individualizado. Tampoco puede negarse tal calificación al mensaje comercial dinámico o estático, siempre que su finalidad sea que los consumidores adquieran sus productos o los usuarios contraten sus servicios. En segundo lugar, la definición de comunicación comercial precisa que la intención de su difusión sea promover la adquisición de los productos o la contratación de los servicios e, incluso, la promoción de la imagen de la entidad anunciante. No considerándose publicidad las comunicaciones que se difundan de modo independiente a la entidad de que se trate y que se hagan sin haber recibido a cambio una contraprestación económica.

En el trabajo que se presenta, nos vamos a ocupar de algunas de las prácticas contrarias a la competencia en el mercado más relevantes y que se llevan a cabo para difundir un producto tan particular como lo es el aceite de oliva en el sector alimenticio y nutricional, así como de las consecuencias o efectos de las mismas desde la perspectiva de la tutela de los intereses de los consumidores.

\section{OBJETIVOS Y METODOLOGÍA}

Los objetivos esenciales que con el estudio que nos ocupa se tratan de alcanzar se concretan en la conceptualización de los comportamientos promocionales que se llevan a cabo en el mercado del sector alimenticio y nutricional, en particular en lo que respecta al aceite de oliva y que suponen prácticas publicitarias contrarias a Derecho. Estos comportamientos, como es sabido, están expresamente indicados en la norma general que regula la actividad publicitaria de los empresarios en el mercado y que, tras la última modificación de la norma de competencia desleal, han sido también recogidos en dicho texto. En este sentido, conviene indicar que la ley que regula los actos desleales en el mercado establece un conjunto de comportamientos desleales con independencia de los destinatarios o sujetos pasivos de los mismos; y otro en el que se engloban unas actuaciones de competencia desleal llevados a cabo por los empresarios o profesionales en sus relaciones con los consumidores y usuarios. Si bien, al objeto de nuestro análisis nos centraremos en ciertas prácticas que afectan a la competencia en el mercado de productos alimenticios y nutricionales y, también, a los consumidores de los mismos, en concreto del aceite de oliva.

A fin de abordar esta materia, la metodología seguida parte de la indicación de los aspectos esenciales de la previsión jurídica de la comunicación publicitaria ilícita en la norma general que le resulta de aplicación y, a continuación, abordaremos la relación de este contenido con el de la calificación de la publicidad contraria a Derecho por la norma de competencia desleal en el mercado. Esencialmente 
porque, en materia de comercialización de un producto como el aceite de oliva, se precisa no sólo el cumplimiento de las normas básicas sobre su promoción, sino también la observancia de los presupuestos necesarios para que el contenido no sea engañoso, la práctica comercial no resulte agresiva y no se incurra en otros planteamientos desleales en lo que concierne al mercado.

Por último, se hará referencia al conjunto de acciones judiciales que el legislador ha propuesto a fin de que el afectado por un acto desleal o, en su caso, por una práctica publicitaria contraria a Derecho pueda defender sus intereses bien a modo particular o a través de asociaciones representativas de ellos y a las que se les reconoce legitimación activa.

\section{RESULTADOS DE LA INVESTIGACIÓN Y DISCUSIÓN}

\section{Referencia a los supuestos de publicidad ilícita en la LGP}

La modificación que se ha hecho al régimen normativo de la competencia desleal en el mercado presenta, entre otras novedades, la previsión de la publicidad considerada ilícita ${ }^{8}$. Para ello, el legislador se remite a las disposiciones de la norma general de publicidad y que le resulta de aplicación prioritaria. Atendiendo al contenido de esta última, necesariamente hemos de acudir al artículo 3 de dicho texto que, como es obvio, también ha sido alterado en sus previsiones iniciales por la mencionada Ley 29/2009.

Los supuestos en los que puede calificarse la publicidad de contraria a Derecho van a ser: la publicidad que atente contra la dignidad de la persona o vulnere los valores y derechos reconocidos en la Constitución, la publicidad dirigida a menores que los incite a la compra de un bien o de un servicio explotando su inexperiencia o credulidad o en la que aparezcan persuadiendo de la compra a padres o tutores; la publicidad subliminal; la que infrinja lo dispuesto en la normativa que regule la publicidad de determinados productos, bienes, actividades o servicios; "la publicidad engañosa, la publicidad desleal y la publicidad agresiva, que tendrán el carácter de actos de competencia desleal en los términos contemplados en la Ley de Competencia Desleal".

Siendo este último apartado el que conforma el punto de inflexión entre las disposiciones de la LGP y las contenidas en la LCD. Así, mientras que ésta afirma la deslealtad de la publicidad de acuerdo con los criterios de su propio contenido; la LGP, por su parte, recoge unos supuestos de ilicitud particulares y otros previstos en la LCD, remitiéndose a aquélla a este respecto.

\footnotetext{
${ }^{8}$ Art. 18 de la LCD.
} 
De los planteamientos de ilicitud indicados, y dejando al margen los recogidos en el texto que se ocupa de la competencia en el mercado y en las relaciones que se suceden en el mismo en las que nos centramos a continuación ${ }^{9}$, consideramos de relevancia detenernos en las prácticas promocionales de naturaleza subliminal y las que son opuestas a lo contenido en la normativa que regula la publicidad de determinados productos, como es el caso de los alimentarios en relación con la promoción del aceite de oliva ${ }^{10}$. La publicidad subliminal es aquélla que a través del empleo de técnicas de producción de estímulos (como pueden ser los medios audiovisuales) actúa sobre los destinatarios sin que sea conscientemente percibida por ellos e influyendo en las decisiones, actitudes e, incluso, en sus actuaciones en el tráfico económico ${ }^{11}$. Por tanto, la pretensión del anunciante es limitar el derecho a percibir y tener conocimiento efectivo de la promoción que está recibiendo el público destinatario, lo cual va en contra del principio de identificación publicitaria previsto como regla general. Y ello, en cuanto que se utiliza el subconsciente de los sujetos para que adopten una determinada decisión sin que posean una correcta y suficiente información, en cuanto que el mensaje promocional no se percibe de manera consciente. No obstante, hay que tener en cuenta que se trata de una práctica de difícil mecanismo probatorio, por cuanto en el supuesto de ser percibida la publicidad subliminal no sería tal, en la medida en que su ilicitud trae su causa en la falta de consciencia sobre el comportamiento promocional.

Por su parte, se considera ilícita la publicidad que contravenga lo previsto en la normativa que regule la promoción de determinados productos. En este aspecto, hay que tener en cuenta que la LGP es de aplicación supletoria respecto de las normas publicitarias de carácter especial que son prioritarias por razón del medio o canal por el que se difunde la publicidad (como lo es el electrónico, los medios audiovisuales o los radiofónicos); del producto que se promociona (como los alimenticios, las bebidas alcohólicas, los medicamentos o el tabaco); o de los destinatarios que la reciben (como el colectivo infantil o los especialmente vulnerables). En este sentido, en el ámbito del sector agroalimentario son diversos los textos vigentes en materia de etiquetado e información sobre los productos alimenticios que, si bien no procede reproducir en este momento, no pueden pasar desapercibidos en la materia ${ }^{12}$. En consecuencia, en la medida en que la comun-

${ }^{9}$ Infra 2. La promoción engañosa, la desleal y la agresiva.

10 Apartados c) y d), del art. 3 de la LGP, respectivamente.

${ }^{11}$ Art. 7 de la LGP. Para ampliar esta materia: J.Mª De La Cuesta Rute, Curso de Derecho de la Publicidad, $2^{\mathrm{a}}$ edic., Pamplona 2002, pp. 132-133; A.Ma. Tobío Rivas, La actual regulación de la publicidad encubierta en España y la práctica publicitaria, "Revista de Derecho Mercantil" 2000, núm. 237 (julio/septiembre), pp. 1184-1186.

${ }_{12}$ En la UE las normas de referencia van a ser: Reglamento (UE) 1169/2011, del Parlamento europeo y del Consejo, de 25 de octubre, sobre la información alimentaria facilitada al consumidor; el Reglamento (UE) 29/2012, de la Comisión, de 13 de enero, sobre las normas de comercialización 
ciación comercial que se haga de un producto agroalimentario y nutricional como lo es el aceite de oliva no respete las disposiciones particulares determinadas por las propias características que lo distinguen, se estaría incurriendo en el supuesto recogido en la LGP de manera expresa y, en consecuencia, la práctica publicitaria se calificaría de ilícita.

\section{La promoción engañosa, la desleal y la agresiva}

La publicidad que resulte engañosa, desleal o, en su caso, agresiva va a ser un supuesto de ilicitud promocional de acuerdo con las previsiones de la LCD. En este sentido, el legislador se remite a las disposiciones contenias en dicha norma para valorar el alcance de estas actuaciones publicitarias en relación con la defensa de los intereses de los afectados en el mercado.

\section{Prácticas publicitarias engañosas}

El engaño en las relaciones comerciales que se suceden en el mercado puede derivarse tanto del contenido de la publicidad que se difunde, como de las omisiones que se hagan en el mismo. Así, de un lado, la norma prevé la deslealtad por engaño de la información falsa o de la que, siendo veraz, induce a error o puede hacerlo a los destinatarios; y que sea susceptible de alterar su comportamiento económico. Además de ello, se ha recogido una lista cerrada de supuestos considerados engañosos en cualquier caso $^{13}$, en la medida en que afectan a quienes

del aceite de oliva; y también el Reglamento (UE) 1308/2013, del Parlamento europeo y del Consejo, de 17 de diciembre, por el que se crea la organización común de mercados de los productos agrarios; así como, diversos Reglamentos Delegados y de Ejecución en ámbitos específicos. Véanse también: la Directiva 2000/13/CE, del Parlamento europeo y del Consejo, de 20 de marzo, relativa a la aproximación de las legislaciones de los Estados miembros en materia de etiquetado, presentación y publicidad de los productos alimenticios (DOUE L 109 de 6 de mayo 2000, cuyo texto ha sido modificado por diversas disposiciones normativas: http://europa.eu/legislation summaries/ consumers/product_labelling_and_packaging/121090_es.htm\#amendingact, acceso: 10.02.2017); y la Directiva 90/496/CEE, del Consejo, de 24 de septiembre, relativa al etiquetado de propiedades nutritivas de los productos alimenticios (DOUE L 276 de 6 de octubre 1990, cuyo texto ha sido modificado por diversas disposiciones normativas: http://europa.eu/legislation summaries/consumers/product_labelling_and_packaging/121092_es.htm, acceso: 10.02.2017). Por su parte, en el ámbito del derecho español, cabe reseñar: el Real Decreto 1334/1999, de 31 de julio, por el que se aprueba la norma general de etiquetado, presentación y publicidad de los productos alimenticios (BOE núm. 202, de 24 de agosto 1999); y el Real Decreto 126/2015, de 27 de febrero, por el que se aprueba la norma general relativa a la información alimentaria de los alimentos que se presenten sin envasar para la venta al consumidor final y a las colectividades, de los envasados en los lugares de venta a petición del comprador, y de los envasados por los titulares del comercio al por menor (BOE núm. 54, de 4 de marzo 2015).

${ }^{13}$ Anexo I 'lista negra' de conductas que se consideran desleales en todo caso y, por tanto, están prohibidas y art. 27 de la LCD. 
ostentan la condición de consumidores. En cuanto a la omisión de datos relevantes en el contenido promocional se plantean dos alternativas: valorar la ilicitud por la omisión u ocultación de información de importancia para los consumidores; o que se ofrezcan los datos, pero de un modo que no resulten claros, inteligibles o que sean ambiguos, o se ofrezcan en un momento inadecuado, o el mencionado contenido no de a conocer su propósito comercial y éste no pueda extraerse del contexto en el que se ofrece. Siempre que ello influya en la toma de decisiones del destinatario con el debido conocimiento de causa y que, de otro modo, no hubiera llevado a cabo ${ }^{14}$. No obstante, para su determinación habrá de tenerse en cuenta el contexto de hecho en cada caso y las características y circunstancias específicas del mismo ${ }^{15}$. Y, en particular, las limitaciones y los aspectos del medio de comunicación empleado y la percepción generada en el consumidor medio ${ }^{16}$. Sin que se precise en estos planteamientos que

${ }^{14}$ Arts. 6 y 7 de la Directiva 2005/29/CE. También los arts. 5 y 7 de la Ley 29/2009 y el art. 49 del TRLDCU.

${ }^{15}$ Algunos autores han señalado que esta apreciación está vacía de contenido, salvo que haga referencia a las características de los medios de comunicación actuales (vide: B. Sainz de Aja Tirapu, La nueva configuración del engaño como ilícito desleal. Comentario a los arts. 5 y 7 de la Ley de Competencia Desleal, [en:] Análisis de la reforma del régimen legal de la competencia desleal y la publicidad llevada a cabo por la Ley 29/2009, de 30 de diciembre, Coord. E. Armijo Chávarri, Madrid 2011, pp. 59-60). El Parlamento europeo ha reconocido en su Resolución de 22 de mayo 2012, sobre el refuerzo de los derechos de los consumidores vulnerables (2011/2272 -INI- para su consulta: www.europarl.europa.eu/sides/getDoc.do?pubRef=-//EP//TEXT+TA+P7-TA-20120209+0+DOC+XML+V0//ES, acceso: 10.02.2017), que la vulnerabilidad de los consumidores, en parte, surge por la falta de comprensión de la información facilitada. Además del desconocimiento de las opciones disponibles o de los mecanismos de reclamación y compensación.

${ }^{16} \mathrm{Cdo} .18$ y apartado $2^{\circ} \mathrm{del}$ art. 5 del texto referenciado. La definición de consumidor medio estaba recogida en la Propuesta inicial de la Comisión (Documento COM (2003) 356 final, de 18 de junio de 2003 [puede consultarse en: www.europa.eu.int/comm/consumers/cons_int/safe shop/fair_bus_pract/directive_prop_es.pdf, acceso: 10.02.2017], relativa a la Posición común adoptada por el Consejo (Documento COM (2004) 753 final de 16 de noviembre de 2004). Resulta de interés la consulta de la Resolución del Parlamento europeo de 22 de mayo 2012, sobre el refuerzo de los derechos de los consumidores vulnerables [2011/2272(INI)], al entenderse que la actual regulación en materia de consumo resulta insuficiente. Vide: C. Fernández-Nóvoa, La Directiva comunitaria sobre prácticas comerciales desleales de las empresas en sus relaciones con los consumidores, "RAAP" 2006, núm. 108, p. 25; J. Massaguer Fuentes, Comentario a la Ley de Competencia Desleal, Madrid 1999, pp. 91-95. El pronunciamiento de referencia sobre el concepto de 'consumidor medio' fue con ocasión de la Sentencia del TJCE, Sala Quinta, de 16 de julio de 1998, Asunto C-210/96, pág. I-04657, en relación con la petición dirigida al Tribunal de Justicia (según el art. 177 del Tratado CE) por el Bundesverwaltungsgericht (Alemania) para obtener, en el litigio pendiente ante dicho órgano entre Gut Springenheide GmbH, Rudolf Tusky y Oberkreisdirektor des Kreises Steinfurt - Amt für Lebensmittelüberwachung, una decisión prejudicial sobre la interpretación de la letra e) del apartado 2 del art. 10 del Reglamento (CEE) $1907 / 90$ del Consejo, de 26 de junio de 1990, relativo a determinadas normas de comercialización de los huevos (DOUE L 173). El TJCE estima que para determinar si una mención que pretende fomentar las ventas de huevos puede inducir a error al comprador (vulnerando la letra e) del apartado 2 del artículo 10 del Reglamento (CEE) 1907/90 del Consejo) se precisa que el juez nacional parta de la expectativa que genere esa mención en un consumidor medio, normalmente 
se induzca o pueda inducir a error al destinatario sobre las características del bien o servicio o suponga una frustración de las expectativas generadas, sino que resulta bastante con que los datos que se omitan sean objetivamente necesarios para que el destinatario tome o pueda llegar a tomar una decisión sobre su comportamiento económico con el suficiente conocimiento. El 'consumidor medio' se caracteriza por estar normalmente informado y ser razonablemente atento y perspicaz, teniendo en cuenta los aspectos sociales, lingüísticos y culturales que le singularizan. A partir de estos calificativos, se presume que el consumidor cuenta con cierto conocimiento e información respecto del contexto en el que se encuentre en cada $\operatorname{caso}^{17}$, a pesar de que no se exija un nivel cultural o académico determinado. Por el contrario, se trata de que tenga una experiencia para interpretar y entender la información que sobre los bienes o servicios recibe en el ámbito comercial. Por tanto, el concepto de consumidor medio no es una referencia estadística, sino que corresponde a los Tribunales y autoridades nacionales de cada uno de los Estados miembros hacer valer sus propios razonamientos a efectos de concretar el comportamiento del consumidor medio, según el supuesto particular de que se trate y teniendo presente la interpretación que sobre este concepto ha hecho el TJCE en sus pronunciamientos judiciales.

Además de ello, ha de tenerse en cuenta el principio general de la clara identificación de los mensajes publicitarios como tales, al igual que de la persona

informado y razonablemente atento y perspicaz (Resolución de 8 de febrero de 1996). Aunque se prevé la posibilidad de que el juez nacional solicite un sondeo de opinión o, en su caso, un dictamen pericial para tomar su decisión en los casos en los que encuentre inconvenientes en su valoración (Apartados 31 y 37 de la Resolución). Caben destacarse otros pronunciamientos anteriores que suponen los antecedentes al concepto de 'consumidor medio': el asunto Boscher de 30 de abril de 1991 (C-239/90, RJTJ pág. I-2023, en particular el Fundamento Jurídico 20); el asunto Yves Rocher de 18 de mayo de 1993 (C-238/89, RJTJ pág. I-4827), el asunto Clinique de 2 de febrero de 1994 (C-126/91, RJTJ pág. I-2361) y el asunto Mars de 6 de julio de 1995 (C-456/93, RJTJ pág. I-1737, en particular el Fundamento Jurídico 24).

${ }^{17}$ El análisis del carácter engañoso o del riesgo de confusión en los consumidores en el empleo de signos distintivos, actividades publicitarias u otros comportamientos en el mercado parte de los mínimos conocimientos e información que se le reconoce al consumidor medio. En relación con ello, destacamos el asunto Darbo de 4 de abril de 2000 (C-465/98, RJTJ p. I-2297) en el que se cuestiona si la expresión puramente natural prevista en una confitura de fresas que contenía pectina y restos o residuos de plomo, cadmio y plaguicidas resultaba engañosa (Fundamento Jurídico 20). El TJCE en los Fundamentos Jurídicos 28 y 29 concluye que el consumidor que adquiere un producto por su composición, previamente va a leer sus ingredientes y, por tanto, la indicación cuestionada no le genera error. Otros asuntos relevantes sobre este concepto son: el asunto Gottfried Linhart (24 de octubre de 2002, C-99/01, RJTJ, p. I-9375); el asunto Renate Sterbenz de 23 de enero 2003 (C-221/00 y a los asuntos acumulados C-421/00, C-426/00 y C-16/01(44)- RJTJ pág. I-1065); el asunto Pippig Augenoptik, de 8 de abril 2003 (C-44/01, RJTJ pág. I-3095); el asunto T-385/03 (Sentencia del Tribunal de Primera Instancia (Sala $4^{\mathrm{a}}$ ), de 7 de julio 2005) que enfrenta a Miles Handelsgesellschaft International $\mathrm{mbH}$ con la Oficina de Armonización del Mercado Interior (OAMI) por el posible riesgo de confusión que puede generar en el consumidor medio la inscripción de la marca figurativa que incluye el elemento denominativo 'Biker Miles' (en negrita con elementos figurativos) y la marca denominativa registrada con anterioridad MILES en relación con productos idénticos o similares. 
en nombre de la cual se realiza la actividad promocional. Y en el caso de que se trate de ofertas, descuentos, premios y regalos, concursos o juegos promocionales la necesidad de que se distingan claramente sus aspectos y que sus condiciones sean fácilmente accesibles y presentadas de modo concreto e inequívoco. Esta idea hace que, además, debamos prestar atención al supuesto de la publicidad encubierta $^{18}$, la cual consiste en enmascarar o encubrir la naturaleza promocional y persuasiva del mensaje bajo formas ajenas a dichos caracteres. Pese a estar relacionada con la publicidad engañosa, no se trata de un supuesto engañoso como tal porque el contenido del mensaje publicitario no lo es. Sino que, por el contrario, lo es la forma a través de la que se difunde la publicidad y, como consecuencia, se hace más vulnerables a los destinatarios, pudiendo incluso afectar a la competencia en el mercado. De forma general, cabe calificar de publicidad encubierta el ejercicio promocional de una entidad que se presenta bajo instrumentos que no son de carácter publicitario, sino meramente informativos ${ }^{19}$.

Por último, hay que aludir a los supuestos publicitarios en los que se presenta una comparación, la cual está jurídicamente permitida si su contenido se adecua a los presupuestos contenidos en la norma ${ }^{20}$. Así, la alusión a un competidor no será ilícita si los bienes que se comparan tienen la misma finalidad o satisfacen iguales necesidades. Además, ha de realizarse una comparación objetiva en relación con aspectos esenciales, pertinentes, verificables y representativos de los mismos. Prohibiéndose la que se haga de la actividad, las prestaciones o el establecimiento propios o ajenos con los de un tercero cuando se refiera a extremos que no sean análogos, relevantes ni comprobables. En este sentido, cuando los productos que se comparan pertenecen a una denominación de origen o indicación geográfica, denominación específica o especialidad garantizada, la comparación sólo podrá efectuarse con otros productos de la misma denominación. Tampoco es posible presentar bienes como imitaciones o réplicas de otros a los que se aplique una marca o nombre comercial que esté debidamente protegido. Finalmente, la norma exige que el contenido comparado no sea engañoso, denigratorio ni suponga una explotación de la reputación ajena en los términos concretos en cada uno de estos comportamientos ${ }^{21}$.

${ }^{18}$ Art. 26 de la LCD. Al respecto, pueden consultarse los trabajos de: J.Ma. De La Cuesta Rute, op. cit., pp. 143 y 167; C. Fernández-Nóvoa, op. cit., p. 187; C. Lema Devesa, La publicidad engañosa en el moderno Derecho español, [en:] Estudios Homenaje al profesor Menéndez, Coord. J.L. Iglesias Prada, Vol. 1, Madrid 1996, p. 873; A. Tato Plaza, La publicidad comparativa, Madrid 1996, pp. 208-210; A.Mª Tobío Rivas, op. cit., pp. 1157-1166.

${ }_{19}$ Vide: J.M ${ }^{\mathrm{a}}$. De La Cuesta Rute, op. cit., p. 166 que, además, menciona la calificación de este tipo de publicidad como "redaccional". Aunque, autores como A.Ma. Tobío Rivas, op. cit., p. 1158, consideran que la finalidad persuasiva no sólo puede conseguirse en un marco informativo, sino que cabe cualquier otro tipo.

${ }^{20}$ Art. 10 de la LCD.

${ }^{21}$ Arts. 5, 7, 9, 12 y 20 de la LCD. 


\section{Prácticas publicitarias agresivas}

La práctica desleal por agresiva ha sido definida de modo genérico por el legislador considerando que lo es cualquier actuación que disminuya o pueda hacerlo de modo significativo la libre elección del destinatario o su conducta sobre un producto o servicio por acoso, coacción, incluido el uso de la fuerza, o influencia indebida, perjudicando o pudiendo perjudicar su comportamiento económico en el mercado ${ }^{22}$. Por tanto, su ilicitud deriva de la concurrencia de ambas exigencias.

La coacción comercial consiste en hacerle creer al consumidor o usuario que tiene que permanecer en el establecimiento hasta que no contrate o adquiera el bien $^{23}$. Por su parte, la influencia debida se apreciará cuando el consumidor o usuario se sienta presionado por el empresario en su situación de superioridad o poder. $\mathrm{El}$ acoso se refiere a la realización de propuestas no solicitadas y persistentes por teléfono, fax, correo electrónico u otros medios de comunicación a distancia, salvo en las circunstancias y en la medida en que esté justificado legalmente para hacer cumplir una obligación contractual ${ }^{24}$. En estos casos, se exige que la entidad emplee mecanismos para que el consumidor pueda oponerse a recibir estas propuestas comerciales no deseadas. Oposición que puede llevarse a cabo mediante una comunicación de voz al número de teléfono con el que se ha identificado el empresario o profesional, o realizarla por escrito a través de un fax, un correo postal o electrónico. Esta referencia normativa se justifica en el perjuicio que para el destinatario genera la recepción de comunicaciones comerciales continuadas y no solicitadas a las cuentas de correo electrónico personales o a medios que pertenecen a un determinado sujeto, como el terminal telefónico móvil o fijo. Pues ello, puede implicar que el receptor vea limitada su capacidad de decisión y no opte por un determinado

${ }^{22}$ Arts. 8 y 9 de la Directiva 2005/29/CE y arts. 8 y 19-30 de la LCD. A ello se añade, por último, un conjunto de prácticas particulares que son calificadas de agresivas per se por afectar a los consumidores y usuarios (art. 31 de la LCD). Este contenido se ha valorado positivamente por autores como F. Díez Estella, Comentario a las "prácticas agresivas» en la Ley de competencia desleal, conforme a la reforma operada por la Ley 29/2009, de 30 de diciembre, por la que se modifica el régimen legal de la competencia desleal y de la publicidad para la mejora de la protección de los consumidores y usuarios, [en:] Análisis de la reforma del régimen legal de la competencia desleal y la publicidad llevada..., pp. 144-145. Aunque para otros (vide: J. Massaguer Fuentes, op. cit., p. 80) la regulación no tiene una delimitación precisa, sino que contiene elementos de dos grupos de prácticas desleales tradicionales: las molestas y la indebida presión de compra.

${ }^{23}$ Art. 28 de la LCD.

${ }^{24}$ Anexo I de la Directiva 2005/29/CE y art. 29 de la LCD. Para ampliar esta materia: I. Gómez-Juárez Sidera, Consideraciones sobre el régimen jurídico del "spam” con ocasión del nuevo artículo 29.2 de la Ley de Competencia Desleal, "Datospersonales.org: La revista de la Agencia de Protección de Datos de la Comunidad de Madrid" 2010, núm. 46; T. Vázquez Ruano, El "spam" y la nueva regulación de la Ley de Competencia Desleal, "Revista de Derecho Mercantil” 2010, núm. 277 (julio/septiembre), pp. 1083-1101. 
bien o servicio en razón de los aspectos objetivos de la oferta recibida, sino por el acoso que dicha conducta comercial le ocasiona.

En todo caso, la valoración del carácter agresivo de un comportamiento en el mercado exige que se preste atención a las características y circunstancias de la actuación. A saber: el momento y el lugar en que se lleva a cabo, su naturaleza o su persistencia; el uso de un lenguaje o comportamiento amenazador o insultante; que el profesional explote cualquier circunstancia grave para reducir la capacidad de decisión del destinatario; otros impedimentos no contractuales onerosos o desproporcionados impuestos por el empresario cuando la contraparte vaya a ejercitar sus derechos legales o contractuales; o la comunicación de que se va a realizar una acción que en el ámbito legal se impide.

Junto a los comportamientos indicados, se regulan supuestos de hecho precisos y referidos a actuaciones comerciales desleales, en todo caso, porque resultan agresivas cuando se ejercen con los consumidores y usuarios ${ }^{25}$. Dichos actos están referidos: de un lado, al establecimiento de obstáculos al ejercicio de los derechos que corresponden al sujeto que es parte en un contrato de seguro; de otro, a la solicitud de devolución del pago, de productos o servicios no solicitados, a menos que se trate de bienes de sustitución; y, por último, la presión al sujeto con la amenaza de perder su trabajo o sustento en el supuesto en el que no desee contratar el producto o servicio promocionado. Planteamientos que por su especialidad no se han incluido en los preceptos específicos en los que se han regulado el resto de prácticas agresivas.

\section{Otros actos desleales}

Además de los actos desleales que hemos valorado con anterioridad y que suponen supuestos de publicidad contraria a Derecho, en el mercado del aceite de oliva se realizan prácticas comerciales que, en ocasiones, perjudican a los que participan de dicho mercado entre los que destacamos no sólo a los consumidores, sino también a los competidores. Nos referimos, a la práctica de venta a pérdida que consiste en determinar un precio bajo coste del producto o bajo precio

${ }^{25}$ La norma se refiere, en particular, a los siguientes: "exigir al consumidor o usuario que desee reclamar una indemnización al amparo de un contrato de seguro, la presentación de documentos que no sean razonablemente necesarios para determinar la existencia del siniestro y, en su caso, el importe de los daños que resulten del mismo o dejar sistemáticamente sin responder la correspondencia al respecto, con el fin de disuadirlo de ejercer sus derechos; exigir el pago inmediato o aplazado, la devolución o la custodia de bienes o servicios suministrados por el comerciante, que no hayan sido solicitados por el consumidor o usuario, salvo cuando el bien o servicio en cuestión sea un bien o servicio de sustitución suministrado de conformidad con lo establecido en la legislación vigente sobre contratación a distancia con los consumidores y usuarios; informar expresamente al consumidor o usuario de que el trabajo o el sustento del empresario o profesional corren peligro si el consumidor o usuario no contrata el bien o servicio". 
de adquisición y que con ello se induzca o se pueda inducir a error a los consumidores acerca del nivel de precios de otros productos del mismo establecimiento, cuando tenga por efecto desacreditar la imagen de un bien o establecimiento ajenos y cuando forme parte de una estrategia encaminada a eliminar a un competidor o grupo de competidores del mercado ${ }^{26}$. Por tanto, para que la venta a pérdida resulte desleal no sólo se precisa la comercialización de un producto como el aceite de oliva a un precio bajo de forma continuada y sin que ello tenga una justificación determinada (rebajas o promociones específicas), sino que se hace con la pretensión de afectar al resto de competidores o que, en su caso, éstos deban salir del mercado en cuestión; y, al mismo tiempo, con ello se induzca a error a los consumidores del mismo. En consecuencia, se reputará desleal si se cumplen los presupuestos indicados, en caso contrario la fijación de precios de productos en el mercado es una libertad amparada en nuestra Constitución para los que desarrollan una actividad empresarial en él ${ }^{27}$.

Junto a lo indicado, podemos hacer referencia a la cláusula general de deslealtad, en la medida en que la práctica promocional enjuiciada no encaje en ninguno de los supuestos específicos determinados en la norma. Un comportamiento será desleal por norma general si resulta objetivamente contrario a las exigencias de la buena $\mathrm{fe}^{28}$, quedando al margen la intencionalidad o el elemento subjetivo de quien realiza la conducta ${ }^{29}$. Esto es, el comportamiento que vulnere las normas objetivas de conducta derivadas del principio de competencia, teniendo en cuenta los imperativos éticos de carácter jurídico y económico ${ }^{30}$. En las relaciones que se llevan a cabo con los consumidores y usuarios resultará opuesto a las exigencias de la buena fe, la conducta o actuación de un profesional que sea contraria a la diligencia que le es exigible y que, con ello, se ocasione o pueda llegar a ocasionarse una distorsión significativa del comportamiento económico del consumidor

${ }^{26}$ Art. 17 de la LCD.

${ }^{27}$ Art. 38 de la Constitución española.

${ }^{28}$ Art. 6 de la Directiva 2005/29/CE y el art. 4 de la LCD que, por su parte, otorga a la buena fe la consideración de base de la cláusula general, junto a la diligencia profesional y las prácticas honradas en el tráfico económico. Por ello, ciertos autores consideran que las cuestiones interpretativas que esta redacción plantea en la práctica, se hubieran podido solventar transcribiendo literalmente el contenido de la norma comunitaria o manteniendo la redacción anterior de la norma (J. Massaguer Fuentes, op. cit., p. 147; A. Robles Martín-Laborda, Art. 4. La cláusula general prohibitiva de la competencia desleal, [en:] Análisis de la reforma del régimen legal de la competencia desleal y la publicidad llevada..., pp. 29-37; y A. Tato Plaza, P. Fernández Carballo-Calero, Ch. Herrera Petrus, La reforma de la Ley de Competencia Desleal, Madrid 2010, p. 66).

${ }^{29}$ Art. 57 del C. de com. y art. 7 del C. civil español, en este último se exige un ejercicio honesto y leal de los derechos.

${ }^{30}$ La cláusula general (art. 4 de la LCD) es una norma completa que tipifica un acto de competencia desleal con sustantividad propia frente al resto de actos de competencia desleal específicos (vide: S. Barona Vilar, Competencia desleal. Tutela Jurisdiccional (especialmente proceso civil) y extrajurisdiccional, Vol. 1, Valencia 2008, p. 312; J. Massaguer Fuentes, op. cit., p. 152; A. Robles 
medio o miembro medio del grupo especialmente vulnerable para adoptar una decisión con pleno conocimiento de causa sobre su comportamiento en el mercado y que no hubiera tomado de no ser por la actuación que distorsiona de manera notable dicho comportamiento. Es decir, que el acto afecte a las decisiones de los consumidores y usuarios respecto a la elección de una oferta o del que la ofrece, la contratación de un producto o servicio y sus condiciones, el abono del pago correspondiente, la conservación del bien o servicio y la ejecución de sus derechos contractuales. Por tanto, la LCD recoge una cláusula general de deslealtad con sustantividad propia y en la que es posible encuadrar los comportamientos o actos desleales que no encajan en las disposiciones específicas previstas en la misma. En definitiva se trata de una previsión o cláusula de cierre ${ }^{31}$ que permite la fácil adaptación a las circunstancias del mercado y el sometimiento al control de deslealtad concurrencial de comportamientos no contemplados de manera expresa en el texto normativo vigente.

\section{Acciones judiciales frente a conductas desleales}

La norma de competencia desleal ha supuesto la unificación del sistema de acciones judiciales y las normas procesales que pueden interponerse en materia de comportamientos desleales y de prácticas publicitarias ${ }^{32}$. En primer término, se establece el ejercicio de la acción declarativa de la ilicitud del comportamiento en el mercado en los supuestos en los que el perjuicio ocasionado se mantenga al momento de su interposición. Por otro lado, se reconoce la posibilidad de interponer las acciones de cesación de la práctica o, cuando corresponda, la prohibición de la misma, en cuanto que aún no se ha llevado a cabo; y la de rectificación en los planteamientos en los que se enjuicien informaciones que sean engañosas, incorrectas o falsas. En otro sentido, la acción de remoción de los efectos que se hubieran producido, es decir que se vuelva a la situación inicial existente antes de realizar el comportamiento contrario a la competencia. Así, se trata de solicitar las medidas necesarias a fin de que desaparezcan los efectos que el acto desleal hubiera provocado. A estas acciones judiciales, se añade la acción de resarcimiento de los daños y perjuicios que se hubieran generado cuando se estime que la práctica se ha llevado a cabo de forma dolosa o culpable por parte del que la ejerce; así como, la acción de enriquecimiento injusto, reconocida únicamente respecto de los comportamientos que impliquen una lesión de la posición jurídica

Martín-Laborda, op. cit., pp. 29-37; J. Sánchez-Calero Guilarte, La ampliación del concepto de competencia desleal, [en:] El Derecho Mercantil en el umbral del siglo XXI, Libro Homenaje al Prof. Dr. Carlos Fernández-Nóvoa, Coord. J.A. Gomez Segade, A. Garcia Vidal, Madrid 2010, pp. 398-399).

${ }^{31}$ Es la conocida como válvula de autorregulación, para ampliar esta idea: S. Barona Vilar, op. cit., p. 312; J. Massaguer Fuentes, op. cit., p. 152; J. Sánchez-Calero Guilarte, op. cit., pp. 398-399.

32 Art. 32 de la LCD y se derogan las especialidades en materia de medidas cautelares y medios de prueba. 
amparada por un derecho de exclusiva u otra de contenido económico equivalente. El ejercicio de las referidas acciones judiciales, además, puede llevar aparejado el acuerdo de la publicación de la sentencia resolutoria por parte del tribunal encargado del enjuiciamiento de la conducta.

La interposición de las acciones indicadas, como es sabido, precisa que el sujeto esté debidamente legitimado para ello. En tal sentido, corresponde la legitimación activa para su interposición a los sujetos que participen en el mercado y cuyos intereses económicos resulten dañados o amenazados directamente ${ }^{33}$. Aunque también es posible que sean ejercitadas por asociaciones, corporaciones profesionales o representativas de los intereses económicos de sus miembros que resulten afectados, asociaciones de consumidores y usuarios; así como, los órganos que en el ámbito comunitario, estatal, autonómico o local, sean competentes en materia de defensa de los consumidores sobre actos desleales y prácticas restrictivas de la competencia; y el Ministerio Fiscal en defensa de los intereses generales, colectivos o difusos de los consumidores y usuarios.

En otro orden, en lo concerniente a la legitimación pasiva, el ejercicio de estas pretensiones se va a llevar a cabo contra el sujeto que ha realizado el comportamiento contrario a la leal competencia en el mercado o, en su caso, hubiera cooperado para que el acto ilícito se pudiese ejercer en el mercado. En un sentido similar, los trabajadores y colaboradores del empresario que realicen sus actuaciones en el marco de las competencias y obligaciones asumidas en la relación contractual con el principal, las acciones declarativas, de cesación, remoción y rectificación deberán interponerse contra este último. De manera específica, la acción de resarcimiento de los daños ocasionados y la de enriquecimiento injusto se dirigirá al que ocasionó el perjuicio de acuerdo con las previsiones del Derecho común.

La prescripción de dichas acciones va a ser de un año desde el momento en que se pudieron ejercitar y el que resulte legitimado para su ejercicio tenga conocimiento de la persona que llevó a cabo el acto enjuiciado ${ }^{34}$. Y, en todo caso, por el transcurso de tres años desde que hubiera finalizado la actuación.

El conjunto de acciones judiciales tendentes a defender y tutelar los intereses de los que participan en el mercado son aplicables tanto a los supuestos de competencia desleal, como a las conductas o comportamientos publicitarios que resulten contrarios a Derecho en aplicación de su propia normativa, pues la reforma jurídica ya aludida ha supuesto la unificación del sistema de acciones ejercitables en materia de competencia desleal y de publicidad.

${ }^{33}$ Art. 33 de la LCD. En el caso de un supuesto de publicidad ilícita la legitimación se extiende a cualquier persona (física o jurídica) afectada y a quienes tengan un derecho subjetivo o interés legítimo.

${ }^{34}$ Art. 35 de la LCD. Cuando se trate de actos contrarios a Derecho que se llevan a cabo de modo continuado o reiterado el cómputo de los plazos temporales previstos será a partir del momento en que no exista el riesgo de repetición de los mismos. 


\section{CONCLUSIONES}

La importancia que tiene la información que las entidades ofrecen en el mercado desde la perspectiva de la toma de decisiones con el debido conocimiento de causa por parte de los que ostentan la condición de consumidores de un determinado producto, como el aceite de oliva o, en su caso, de usuarios de un servicio, hace que deba valorarse desde dos perspectivas. De un lado, como mecanismo de tutela y garantía de los intereses de los consumidores y usuarios; y, de otro, en relación con los actos de competencia desleal de los empresarios en sus relaciones con los mismos.

El legislador español ha transpuesto las previsiones de la Directiva comunitaria sobre las prácticas comerciales desleales de las empresas en sus relaciones con los consumidores en el mercado interior, esencialmente modificando el contenido de la norma de competencia desleal y el régimen de la publicidad. Si bien, cabe poner de manifiesto que no ha hecho, a nuestro entender, con el mismo acierto en todo su contenido. De modo genérico, la LCD establece como actos de competencia desleal con independencia de quien resulte destinatario, las acciones y omisiones engañosas y las prácticas agresivas. Tras esta previsión, y siguiendo las disposiciones comunitarias en relación con las conductas engañosas y agresivas per se, se ha recogido de modo concreto una regulación de dichas prácticas desleales con los consumidores. La pretensión de este reconocimiento no es otra que conseguir un adecuado nivel de protección de los consumidores que participan en el mercado, tratando de conferir confianza y seguridad en las relaciones comerciales que se llevan a cabo con los empresarios o profesionales. Sin embargo, estas disposiciones, en ocasiones, generan una dualidad regulatoria no justificada. No obstante, en otros aspectos como los referidos al régimen de las acciones judiciales y el procedimiento de defensa de los intereses afectados por determinados comportamientos en el mercado, ha salvado la divergencia existente entre el anterior contenido de la norma publicitaria y el recogido en la ley de competencia desleal, superando las dificultades que se planteaban en la práctica comercial.

\section{BIBLIOGRÁFIA}

El nuevo Derecho contra la competencia desleal. La Directiva 2005/29/CE sobre las Prácticas Comerciales Desleales, Pamplona 2006.

Barona Vilar S., Competencia desleal. Tutela Jurisdiccional (especialmente proceso civil) y extrajurisdiccional, Vol. 1, Valencia 2008.

De La Cuesta Rute J.M ${ }^{\mathrm{a}}$., Curso de Derecho de la Publicidad, $2^{\mathrm{a}}$ edic., Pamplona 2002.

Diez Estella F., Comentario a las «prácticas agresivas» en la Ley de competencia desleal, conforme a la reforma operada por la Ley 29/2009, de 30 de diciembre, por la que se modifica el régimen legal de la competencia desleal y de la publicidad para la mejora de la protección 
de los consumidores y usuarios, [en:] Análisis de la reforma del régimen legal de la competencia desleal y la publicidad llevada a cabo por la Ley 29/2009, de 30 de diciembre, Coord. E. Armijo Chávarri, Madrid 2011.

Fernández-Nóvoa C., La Directiva comunitaria sobre prácticas comerciales desleales de las empresas en sus relaciones con los consumidores, "RAAP" 2006, núm. 108.

Gómez-Juárez Sidera I., Consideraciones sobre el régimen jurídico del "spam" con ocasión del nuevo artículo 29.2 de la Ley de Competencia Desleal, "Datospersonales.org: La revista de la Agencia de Protección de Datos de la Comunidad de Madrid" 2010, núm. 46.

Lema Devesa C., La publicidad engañosa en el moderno Derecho español, [en:] Estudios Homenaje al profesor Menéndez, Coord. J.L. Iglesias Prada, Vol. 1, Madrid 1996.

Massaguer Fuentes J., Comentario a la Ley de Competencia Desleal, Madrid 1999.

Prácticas comerciales agresivas, [en:] Publicidad, defensa de la competencia y protección de datos, Pamplona 2010.

Robles Martín-Laborda A., Art. 4. La cláusula general prohibitiva de la competencia desleal, [en:] Análisis de la reforma del régimen legal de la competencia desleal y la publicidad llevada a cabo por la Ley 29/2009, de 30 de diciembre, Coord. E. Armijo Chávarri, Madrid 2011.

Sainz de Aja Tirapu B., La nueva configuración del engaño como ilícito desleal. Comentario a los arts. 5 y 7 de la Ley de Competencia Desleal, [en:] Análisis de la reforma del régimen legal de la competencia desleal y la publicidad llevada a cabo por la Ley 29/2009, de 30 de diciembre, Coord. E. Armijo Chávarri, Madrid 2011.

Sanchez-Calero Guilarte J., La ampliación del concepto de competencia desleal, [en:] El Derecho Mercantil en el umbral del siglo XXI, Libro Homenaje al Prof. Dr. Carlos Fernández-Nóvoa, Coord. J.A. Gomez Segade, A. Garcia Vidal, Madrid 2010.

Tato Plaza A., La publicidad comparativa, Madrid 1996.

Tato Plaza A., Fernandez Carballo-Calero P., Herrera Petrus Ch., La reforma de la Ley de Competencia Desleal, Madrid 2010.

Tobío Rivas A.M‥, La actual regulación de la publicidad encubierta en España y la práctica publicitaria, "Revista de Derecho Mercantil" 2000, núm. 237 (julio/septiembre).

Vázquez Ruano T., El "spam" y la nueva regulación de la Ley de Competencia Desleal, "Revista de Derecho Mercantil” 2010, núm. 277 (julio/septiembre).

\section{STRESZCZENIE}

Rynek jest podstawowym źródłem informacji o istotnym znaczeniu dla konsumenta oraz miejscem nieustającego oddziaływania na siebie podaży i popytu. Zadaniem przedsiębiorcy jest podjęcie próby przyciągnięcia uwagi konsumenta przez przesyłanie komunikatów mających na celu zwrócenie uwagi ich odbiorcy oraz przy okazji reklamy swojego produktu, jak np. oliwa z oliwek. W przedmiotowym zakresie może znaleźć zastosowanie dyrektywa 2005/29/WE Parlamentu Europejskiego i Rady z dnia 11 maja 2005 r. dotycząca nieuczciwych praktyk handlowych stosowanych przez przedsiębiorstwa wobec konsumentów na rynku wewnętrznym, która spowodowała konieczność zmiany ustawodawstwa hiszpańskiego regulującego problematykę konkurencji rynkowej oraz działalności reklamowej. Prawodawca krajowy wykorzystał tę okoliczność również dla określenia tzw. reklamy niezgodnej z prawem, którą uznał za jedną z form nieuczciwej konkurencji. Doprowadzono tym samym do ujednolicenia systemu rozwiązań prawnych przeciwdziałających rynkowym działaniom bezprawnym.

Słowa kluczowe: nieuczciwa konkurencja; reklama; oliwa z oliwek; wprowadzanie do obrotu; ochrona konsumenta 